\title{
ОСОБЕННОСТИ ТЕЧЕНИЯ БЕРЕМЕННОСТИ И ВЕДЕНИЯ РОДОВ, ИСХОДОМ КОТОРЫХ БЫЛО РОЖДЕНИЕ НОВОРОЖДЕННОГО В СОСТОЯНИИ ТЯЖЕЛОЙ АСФИКСИИ
}

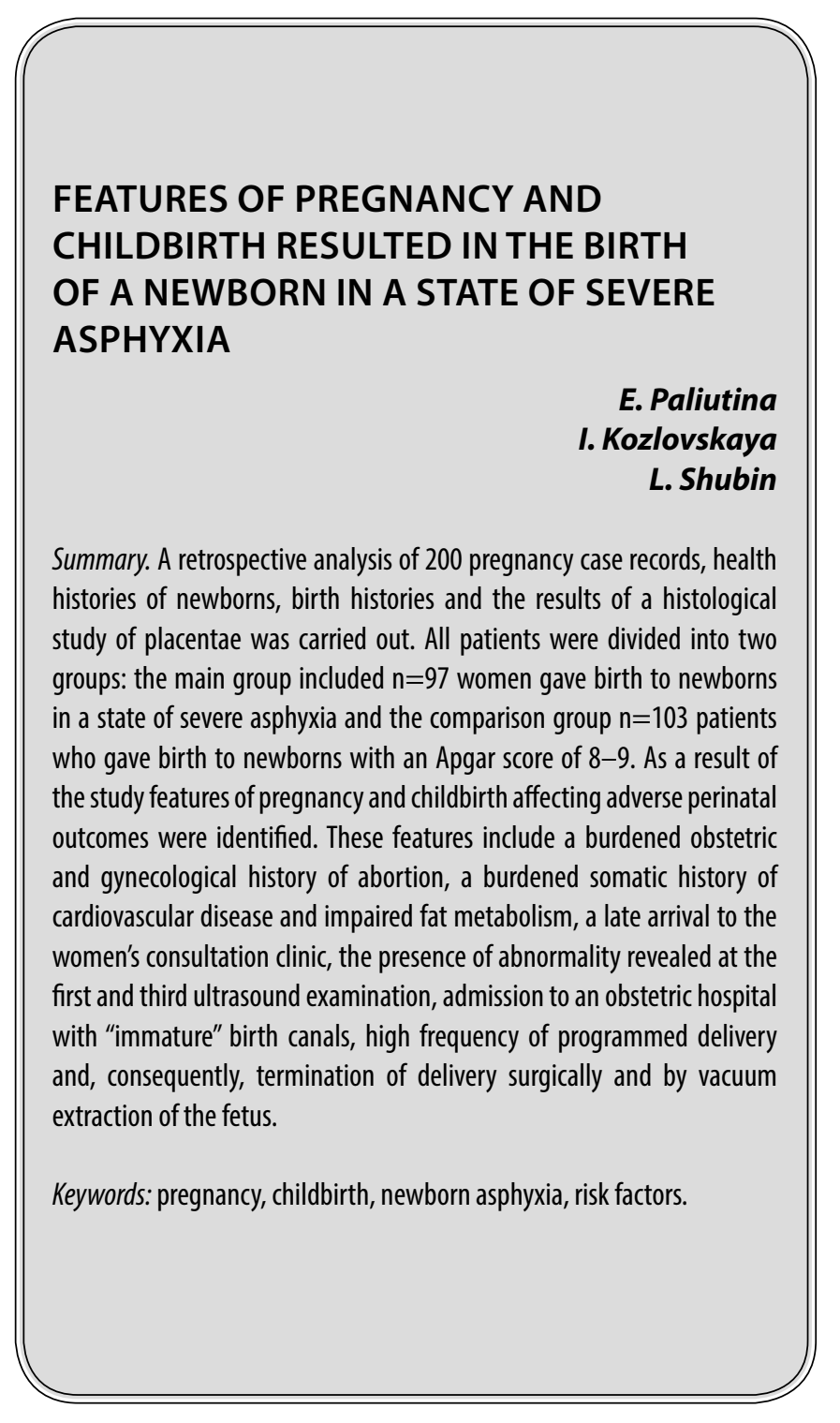

3 а последнее время акушерские причины перинатальных потерь и их частота в регионах Российской Федерации практически остается прежними: это некачественное наблюдение за беременными, ведение родов, особенно в областных населенных пунктах при отсутствии единых стандартов и протоколов по оказанию медицинской помощи беременным, роженицам и родильницам. Конечная цель беременности и родов - это не количество, родившихся живыми младенцев, а рождение здорового поколения, способного в бу-
Палютина Елена Юрьевна

К.м.н., дочент, ФГБОУВО «Ярославский государственный медицинский университет» Минздрава России peyu260562@mail.ru

Козловская Ирина Александровна К.м.н., врач акушер-гинеколог, ГБУЗ Ярославской области «Областной перинатальный чентр» kia801980@mail.ru

Шубин Леонид Борисович

К.м.н., дочент, ФГБОУ ВО «Ярославский государственный медицинский университет» Минздрава России

LBSH@yandex.ru

Аннотация. Был проведен ретроспективный анализ 200 диспансерных книжек, истории родов, историй новорожденных и результаты гистологического исследования последов. Группы были сформированы методом случайной выборки. Основным критерием отбора явилась оценка новорожденного по шкале Апгар на первой минуте жизни. В основную группу вошли $\mathrm{n}=97$ женщины, родившие новорожденных в состоянии тяжелой асфиксии и группу сравнения - n=103 пациентки, родившие новорожденных с оценкой по шкале Апгар 8-9 баллов. В результате исследования были выявлены особенности течения беременности и родов, влияющие на неблагоприятные перинатальные исходы. К этим особенностям относятся отягощенный акушерско-гинекологический анамнез по абортам, отягощенный соматический анамнез по сердечно-сосудистой патологии и нарушению жирового обмена, поздняя явка в женскую консультацию, наличие патологии, выявленной на первом и третьем ультразвуковом исследовании, поступление в акушерский стационар с «незрелыми» родовыми путями, высокая частота программированных родов и как следствие завершение родов оперативным путем и вакуум экстракцией плода.

Ключевые слова: беременность, роды, асфиксия новорожденных, факторы риска.

дущем обеспечивать себя и способного воспроизвести здоровое потомство.

В последнее время были опубликованы результаты исследований, которые подтвердили связь полиморфизма генов CSTT1, CSTM1, CSTP1 и развитием тяжелой асфиксии у доношенных новорожденных. (Будюхина О.А. и др.) Проведение подобных исследований возможно только в научно-исследовательских учреждениях федерального уровня. Мы же имеем возможность лишь 
Таблица 1. Особенности социально-медицинских факторов пациенток в группах сравнения

\begin{tabular}{|c|c|c|c|c|c|c|}
\hline социальные -медицинские факторы & $\mathrm{N}=97$ & & $\mathrm{~N}=10$ & & $p<0,05$ & Kendall Tau \\
\hline возраст & 30,23 & & 29,42 & & & \\
\hline рост & 161,9 & & 164,9 & & $\mathrm{p}<0,001$ & $-0,2$ \\
\hline вес при постановке на учет & 67,4 & & 62,6 & & $\mathrm{p}<0,025$ & 0,08 \\
\hline ИМт & 25,4 & & 22,9 & & $\mathrm{p}<0,000$ & 0.14 \\
\hline состоят в браке & 67 & $69,1 \%$ & 79 & $76,9 \%$ & & \\
\hline имеют среднее образование & 14 & $14,4 \%$ & 10 & $9,7 \%$ & & \\
\hline имеют среднее профессиональное образование & 33 & $34 \%$ & 22 & $21,4 \%$ & $p<0,0456$ & 0,14 \\
\hline имеют высшее образование & 49 & $50,5 \%$ & 71 & $68,9 \%$ & $p<0,008$ & $-0,187$ \\
\hline наличие работы & 69 & $71,1 \%$ & 78 & $75,7 \%$ & & \\
\hline проживают в г. Ярославль & 49 & $50,5 \%$ & 73 & $70,9 \%$ & $p<0,0033$ & $-0,21$ \\
\hline проживают в Ярославском районе & 12 & $12,4 \%$ & 7 & $6,8 \%$ & & \\
\hline проживают в Ярославской области & 34 & $35,1 \%$ & 23 & $22,3 \%$ & $p<0,0469$ & 0,14 \\
\hline
\end{tabular}

Таблица 2. Показатели паритета и анамнеза в группах сравнения

\begin{tabular}{|l|l|l|l|l|l|l|}
\hline паритет & \multicolumn{2}{|l|}{$\mathbf{N = 9 7}$} & $\mathbf{N}=103$ & $\mathbf{p}<0,05$ & Kendall Tau \\
\hline количество беременностей & 2,59 & & 2,11 & & \\
\hline количество родов & 1,63 & & 1,77 & & & \\
\hline количество абортов & $\mathbf{0 , 6 2}$ & & $\mathbf{0 , 1 3}$ & & $\mathbf{p}<0,000$ & $\mathbf{0 , 2 5}$ \\
\hline количество выкидышей & 0,33 & & 0,25 & & & \\
\hline первобеременные первородящие & 40 & $41 \%$ & 39 & $38 \%$ & & \\
\hline Повторнобеременные первородящие & $\mathbf{1 9}$ & $\mathbf{1 9 , 6 \%}$ & $\mathbf{2}$ & $\mathbf{1 , 9 \%}$ & $\mathbf{p}<0,001$ & \\
\hline Повторонобеременные повторнородящие & $\mathbf{3 8}$ & $\mathbf{4 0 \%}$ & $\mathbf{6 2}$ & $\mathbf{6 0 , 1} \%$ & $\mathbf{p}<0,005$ & \\
\hline имеют ОАГА & $\mathbf{5 0}$ & $\mathbf{5 1 , 5 \%}$ & $\mathbf{2 8}$ & $\mathbf{2 7 , 2 \%}$ & $\mathbf{p}<0,002$ & $\mathbf{- 0 , 2 2}$ \\
\hline
\end{tabular}

ориентироваться на те данные, которые были получены при стандартном обследовании беременной в условиях женской консультации и стационара.

В ранее опубликованной нами статье «Медико-социальные факторы риска тяжелой асфиксии новорожденных» был сформулирован профиль пациентки, угрожаемой по рождению плода с низкой оценкой по шкале Апгар, что нашло подтверждение и в данном исследовании. Это беременные около 30лет, проживающие в малонаселенных городах Ярославской области, с ростом ниже среднего, с ожирением, со средне-профессиональным образованием. При этом влияния таких переменные как наличие зарегистрированного брака и официального трудоустройства на возможность рождения плода в состоянии тяжелой асфиксии не выявлено.

\section{Цель нашего исслеАования}

Выявить особенности гистологического строения последов, факторы риска течения беременности, ведения родов, исходом которых было рождение плода в состоянии тяжелой асфиксии.

\section{Материалы и метомы}

Был проведен ретроспективный анализ диспансерных книжек, протоколов ультразвукового исследования, историй родов, протоколов патоморфологического исследования последов и историй новорожденных, родившихся в областном перинатальном центре города Ярославля в 2016-2019 годах. Группы были сформированы методом случайной выборки. Основным критерием отбора явилась оценка новорожденного по шкале Апгар на первой минуте жизни. В основную группу вошли $\mathrm{n}=97$ женщины родившие новорожденных в состоянии тяжелой асфиксии, а в группу сравнения - $\mathrm{n}=103$ пациентки, родившие новорожденных с оценкой по шкале Апгар 8-9 баллов Критериями исключения были срок родоразрешения менее 34 недель, в связи с наличием синдрома дыхательных расстройств характерного для данного срока гестации, многоплодная беременность, наличие врожденных пороков развития плода. Статистическую обработку полученных данных проводили с помощью программы SPSS22. По каждому признаку в сравниваемых группах, определяли среднее значение со стандартным отклонением, сравнивая исследуемые 
Таблица 3. Особенности соматического анамнеза пациенток в группах сравнения

\begin{tabular}{|c|c|c|c|c|c|c|}
\hline соматический анамнез & $\mathrm{N}=\mathrm{c}$ & & $\mathbf{N}=$ & & $p<0,05$ & Kendall Tau \\
\hline имеют патологию с.с.с. & 36 & $37,1 \%$ & 7 & $6,80 \%$ & $p<0,0000$ & 0,37 \\
\hline имеют патологию ж.к.т. & 16 & $17 \%$ & 16 & $15,5 \%$ & & \\
\hline имеют эндокринную патологию & 39 & $40,2 \%$ & 36 & $35 \%$ & & \\
\hline имеют нарушение жирового обмена & 20 & $20,6 \%$ & 7 & $6,8 \%$ & $p<0,0043$ & 0,2 \\
\hline имеют железодефицитную анемию & 38 & $39,2 \%$ & 35 & $34 \%$ & & \\
\hline имеют инфекцию мочевыводящих путей & 29 & $29,9 \%$ & 16 & $15,5 \%$ & $p<0,0153$ & 0,17 \\
\hline наличие резус-отрицательной крови & 8 & $8,2 \%$ & 25 & $24,3 \%$ & $p<0,0023$ & $-0,22$ \\
\hline наличие варикозной болезни & 10 & $10,3 \%$ & 12 & $11,7 \%$ & & \\
\hline наличие хронических инфекций & 17 & $17,5 \%$ & 12 & $11,7 \%$ & & \\
\hline наличие сифилиса, гепатита В, С, ВИЧ-инфекции & 6 & $6,2 \%$ & 3 & $2,9 \%$ & & \\
\hline наличие миопии & 35 & $36,1 \%$ & 31 & $30,1 \%$ & & \\
\hline
\end{tabular}

Таблица 4. Результаты обследование при беременности пациенток в группах сравнения

\begin{tabular}{|l|l|l|l|l|l|l|}
\hline Обследование при беременности & N=97 & N=103 & p<0,05 & $\begin{array}{l}\text { Kendall } \\
\text { Tau }\end{array}$ \\
\hline наличие ранней явки до 12 недель & 76 & $\mathbf{7 8 , 4 \%}$ & $\mathbf{1 0 0}$ & $\mathbf{9 7 , 1 \%}$ & $\mathbf{p}<0,0000$ & $-0,29$ \\
\hline отсутствии патологии при скриниговом УзИ № 1 & 69 & $\mathbf{7 1 , 1 \%}$ & $\mathbf{1 0 0}$ & $\mathbf{9 7 , 1 \%}$ & $\mathbf{p}<0,0000$ & $-0,36$ \\
\hline $\begin{array}{l}\text { отсутствие патологии выявленной при скриниговом } \\
\text { УзИ № 2 }\end{array}$ & $\mathbf{7 8}$ & $\mathbf{8 4 , 8 \%}$ & $\mathbf{9 8}$ & $\mathbf{9 6 , 1 \%}$ & $\mathbf{p}<0,0069$ & $-0,19$ \\
\hline $\begin{array}{l}\text { отсутствие патологии выявленной при скриниговом } \\
\text { УзИ № 3 }\end{array}$ & $\mathbf{6 1}$ & $\mathbf{6 4 , 9 \%}$ & $\mathbf{9 2}$ & $\mathbf{9 0 , 2 \%}$ & $\mathbf{p}<0,0000$ & $-0,31$ \\
\hline наличие патология околоплодных вод & $\mathbf{2 8}$ & $\mathbf{2 8 , 9 \%}$ & $\mathbf{1}$ & $\mathbf{1 \%}$ & $\mathbf{p}<0,0000$ & 0,39 \\
\hline свободная субъединица ХГТ & $\mathbf{4 3 , 2 2}$ & & $\mathbf{3 5 , 4}$ & & $\mathbf{p}<0,046$ & 0,17 \\
\hline
\end{tabular}

группы с помощью t-критерия Стьюдента, корреляционную зависимость количественных и качественных факторов. Значимость исследуемых факторов риска была подтверждена с помощью вычисления отношения шансов (OR).

\section{Результаты исслемования}

При сравнении групп между собой в результате проведенного исследования не было выявлено достоверной разницы между группами по следующим показателям: по количеству беременностей, родов и самопроизвольных выкидышей. Но, при этом была выявлена не только достоверная разница между группами $(p \leq 0,0005)$ по количеству искусственных абортов, но и достоверная $(\mathrm{p} \leq 0,0000)$ положительная корреляционная связь с тяжелой асфиксией. И как следствие у повторнобеременных, но первородящих шансов на неблагоприятные перинатальные исходы значительно выше, чем у повторнобеременных, повторонородящих женщин.

Обращает на себя внимание тот факт, что к 30 годам больше половины пациенток основной группы имели отягощенный акушерско-гинекологический анамнез не только с высокой достоверностью, но и с обратной корреляционной зависимостью с тяжестью состояния плода при рождении.

При анализе анамнеза пациенток следует отметить, что к 30 годам естественным образом увеличивается количество соматических заболеваний. Но в основной группе не только достоверно больше сердечно-сосудистой патологии (гипертензия, гипотония), нарушений жирового обмена, инфекций мочевыводящих путей, но и выявлена прямая корреляционная зависимость с тяжелой асфиксией плода при рождении.

Случайно был выявлен очень интересный факт: в группе сравнения четверть женщин имели резус отрицательную кровь, но без изосенсибилизации, достоверно больше, чем в основной группе, причем с отрицательной корреляционной зависимостью к тяжелой асфиксии новорожденного. Объяснения этому факту в научной литературе мы не нашли.

Мы проанализировали данные обследования беременных женщин в условиях женской консультации. В результате анализа было выявлено, что только 78\% жен- 
Таблица 5. Особенности течения родов в группах сравнения

\begin{tabular}{|c|c|c|c|c|c|c|}
\hline \multirow{2}{*}{$\begin{array}{l}\text { течение родов } \\
\text { продолжительность } 1 \text { периода }\end{array}$} & \multicolumn{2}{|l|}{$N=97$} & \multicolumn{2}{|l|}{$\mathrm{N}=103$} & \multirow{2}{*}{$\begin{array}{l}p<0,05 \\
p<0,008\end{array}$} & \multirow{2}{*}{$\begin{array}{l}\text { Kendall Tau } \\
0,15\end{array}$} \\
\hline & 328,1 & & 271,4 & & & \\
\hline продолжительность 2 периода & 28,62 & & 18,96 & & $p<0,01$ & 0,35 \\
\hline безводный промежуток (мин) & 557 & & 344 & & $p<0,001$ & 0,23 \\
\hline преждевременный разрыв плодного пузыря & 47 & $48,6 \%$ & 43 & $41,7 \%$ & & \\
\hline наличие патологии околоплодных вод & 28 & $28,9 \%$ & 1 & $0,9 \%$ & $p<0,0000$ & 0,39 \\
\hline $\begin{array}{l}\text { состояние родовых путей при поступление } \\
\text { в стационар }\end{array}$ & & & & & & $-0,71$ \\
\hline незрелая шейка матки & 71 & $73 \%$ & 2 & $1,94 \%$ & $p<0,0000$ & \\
\hline зрелая шейка матки & 21 & $21,6 \%$ & 39 & $37,86 \%$ & $p<0,0000$ & \\
\hline с открытием маточного зева & 5 & $5,2 \%$ & 62 & $60,19 \%$ & $p<0,0000$ & \\
\hline \multicolumn{7}{|l|}{ индукция родов } \\
\hline катетор Фоллея & 35 & $36,1 \%$ & 0 & $0,00 \%$ & $p<0,0000$ & 0,47 \\
\hline мифепристон & 17 & $17,5 \%$ & 0 & $0,00 \%$ & $p<0,0000$ & 0,31 \\
\hline динопрост-гель & 10 & $10,3 \%$ & 0 & $0,00 \%$ & $p<0,0000$ & 0,23 \\
\hline амниотомия & 37 & $38,14 \%$ & 0 & $0,00 \%$ & $p<0,0000$ & 0,49 \\
\hline родовозбуждение окситоцином & 38 & $39,2 \%$ & 9 & $8,7 \%$ & $p<0,0000$ & 0,36 \\
\hline $\begin{array}{l}\text { оперативное родоразрешение путем } \\
\text { кесарева сечения }\end{array}$ & 38 & $39,2 \%$ & 13 & $12,6 \%$ & $p<0,0000$ & 0,3 \\
\hline вакуум-экстракция плода & 47 & $48,6 \%$ & 5 & $4,9 \%$ & $p<0,0001$ & 0,27 \\
\hline масса плода & 3167,9 & & 3333,7 & & $p<0,037$ & $-0,066$ \\
\hline
\end{tabular}

щин ( $\mathrm{p} \leq 0,0000)$, родивших новорожденных в состоянии тяжелой асфиксии встали на диспансерный учет до 12 недель беременности, достоверно $(p \leq 0,0000)$ доказано, что поздняя явка в женскую консультацию на прямую связана с высоким перинатальным риском.

При изучении объема обследования в условиях женской консультации следует отметить, что только $71 \%$ беременных основной группы $(p \leq 0,0000)$ прошли перинатальный скрининг в сроках 11-14 недель в сравнении с 97\% пациенток группы сравнения с доказанной $(p \leq 0,0000)$ обратной корреляционной зависимостью с тяжелой асфиксией. При анализе протоколов ультразвуковых исследований было выявлено, что только у 71,1\% пациенток при УЗИ № 1, у 84,4\% пациенток при УЗИ № 2 и у 64,9\% пациенток при УЗИ № 3 патологии не было выявлено, что достоверно отличало основную группу от группы сравнения. Выявлена отрицательная взаимосвязь между результатами ультразвукового исследования, особенно в первом и третьем триместрах беременности и возможностью рождения плода в состоянии тяжелой асфиксии.

При анализе данных биохимического скрининга таких как размер ТВП, КТР, количества свободных субъединиц ХГТ и РАРР и ХГТ в Момах и РАРР в Момах достоверная разница между группами и слабая положительная корреляционная связь с тяжелой асфиксией была выявлена только по количеству свободной субъединицы ХГТ. При ультразвуковом обследовании в сроках доношенной беременности в основной группе в $28,9 \%$ случаях $(p \leq 0,0000)$ против 1\% в группе сравнения было выявлено либо маловодие, либо многоводие с доказанной $(p \leq 0,0000)$ прямой корреляционной связью с состоянием тяжелой асфиксией.

При анализе историй родов были отмечены интересные факты: преждевременный разрыв плодных оболочек в исследуемых группах отмечался практически с одинаковой частой - 48,4\% в основной группе и 41,7\% в группе сравнения, не было выявлено и корреляционной связи с рождением плода в состоянии тяжелой асфиксии, а вот продолжительность безводного промежутка достоверно $(p \leq 0,001)$ отличалась в сравниваемых группах - в среднем 9,28 часа в основной группе и в среднем 5,73 часа в группе сравнения с доказанной $(p \leq 0,0000)$ прямой корреляционной связью с тяжелой асфиксией. При поступлении в акушерское отделение оценивали состояние родовых путей. Была выявлена существенная достоверная разница $(p \leq 0,0000)$ между исследуемыми группами: в основной группе только 5\% женщин поступили в первом периоде родов против $60 \%$ пациенток в группе сравнения, 22\% беременных основной группы и 38\% группы сравнения имели «зрелые» 
Таблица 6. Показания к операции кесарево сечение в основной группе

\begin{tabular}{|l|l|}
\hline Показания к операции кесарево сечение — всего 38 случаев & $\%$ \\
\hline Дистресс плода & 47,3 \\
\hline Частичная отслойка нормально расположенной плаценты, кровотечение & 15,7 \\
\hline Выпадение петель пуповины & 10,5 \\
\hline Предлежание плаценты, кровотечение & 7,9 \\
\hline Нарушение фето-плацентарного кровотока & 7,9 \\
\hline Неэффективность родовозбуждения & 5,3 \\
\hline Вторичная слабость родовой деятельности & 2,7 \\
\hline Косое положение плода & 2,7 \\
\hline
\end{tabular}

родовые пути $(p \leq 0,05)$ и наиболее важным является тот факт, что 73\% женщин, родивших детей в состоянии тяжелой асфиксии поступили в стационар с «незрелыми» родовыми путями против $2 \%$ в группе сравнения, что потребовало в последствии использование методов индукции родов. Состояние родовых путей при поступлении в акушерский стационар имело обратную корреляционную связь $(p \leq 0,0000)$ с тяжелой асфиксией.

Этот факт отразился на дальнейшей тактике ведения пациенток основной группы, в которой достоверно ( $\leq \leq 0,0000)$ чаще в $18 \%$ случаев использовали мифепристон - в группе сравнения не применялся, в 10\% случаев гель - в группе сравнения не применялся, и в $36 \%$ против 1\% катетер Фоллея для подготовки родовых путей. Для родовозбуждения в основной группе достоверно ( $\mathrm{p} \leq 0,0000)$ чаще использовали амниотомию $40 \%$ против 1\% в группе сравнения и в 39\% случаев внутривенное введение окситоцина по общепринятой схеме против 9\% в группе сравнения с доказанной $(p \leq 0,0000)$ прямой корреляционной связью с тяжелой асфиксией.

Сравниваемые группы достоверно (ps0,0001) отличались по сроку родоразрешения в среднем 38,4 22,08 недель беременности в основной группе и в среднем $39,3 \pm 0,97$ недель беременности в группе сравнения с доказанной $(p \leq 0,0006)$ обратной корреляционной связью с тяжелой асфиксией.

В обеих группах во втором периоде родов для извлечения плода был использован вакуум-экстрактор - достоверно чаще ( $p \leq 0,0001) 26 \%$ в основной группе и только в $5 \%$ в группе сравнения с доказанной $(p \leq 0,0000)$ прямой корреляционной связью с тяжелой асфиксией.

В группе сравнения 99\% женщин ( $\leq \leq 0,0000)$ родоразрешились через естественные родовые пути, а в основной группе только $61 \%$ пациенток с доказанной $(p \leq 0,0000)$ обратной корреляционной зависимостью с тяжелой асфиксией.
Основным показанием для оперативного родоразрешения был дистресс плода, открытым остается вопросчем он был вызван? - хронической плацентарной недостаточностью, внутриутробной задержкой роста плода, неадекватным использованием методов индукции родов. На втором месте это - частичная отслойка нормально расположенной плаценты, кровотечение, что является абсолютным показанием для кесарева сечения при невозможности родоразрешения через естественные родовые пути.

Масса новорожденных в сравниваемых группах до-

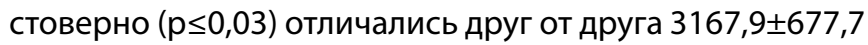
грамм в основной группе и 3333,6 411,4 грамм в группе сравнения при этом корреляционной зависимости с тяжелой асфиксией не обнаружено. Новорожденные были оценены по шкале Апгар на первой и пятой мину-

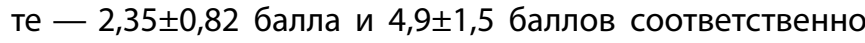

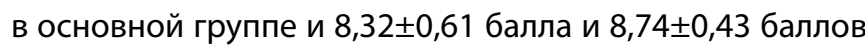
в группе сравнения.

Основной причиной гипоксии плода являются морфофункциональные нарушения плаценты, которые могут не иметь клинических проявлений в антенатальном периоде, а в стрессовой ситуации родов являются фактором, определяющим декомпенсацию с развитием клинически значимой гипоксии плода. (Низяева Н.В., Приходько А.М., Евграфова А.В. и др.)

Морфологическую основу хронической плацентарной недостаточности представляет патология фетоплацентарного комплекса: циркуляторные расстройства, инволютивно - дистрофические процессы, гипоплазия плаценты, диффузное воспаление, нарушение компенсаторно-приспособительных реакций (КПР) в плаценте. (Е.И. Барановская, О.А. Будюхина, С.А. Баранчук)

На патоморфологическое исследование были отправлены 89 последов основной группы, родивших детей в состоянии тяжелой асфиксии. 


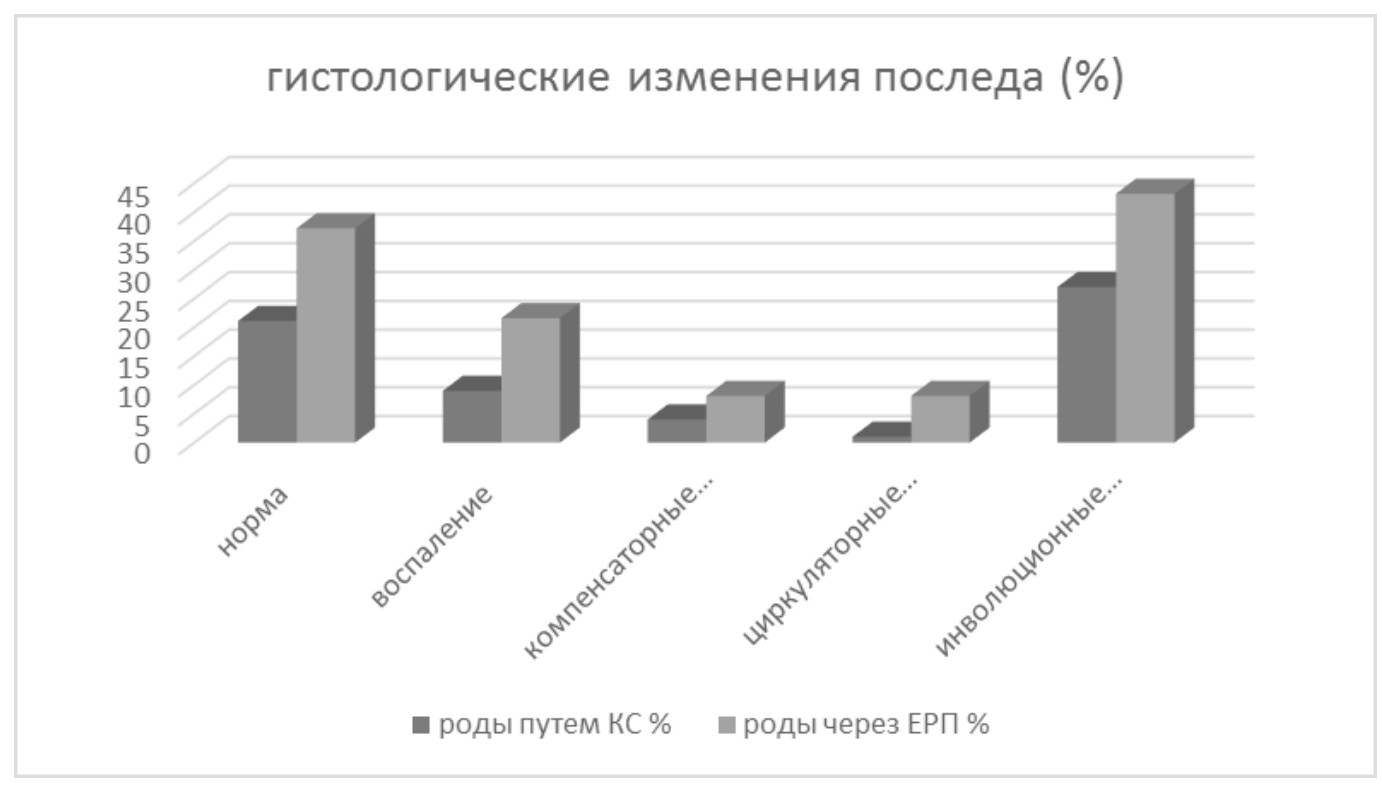

Диаграмма 1. Гистологические изменения последов основной группы в зависимости от метода родоразрешения

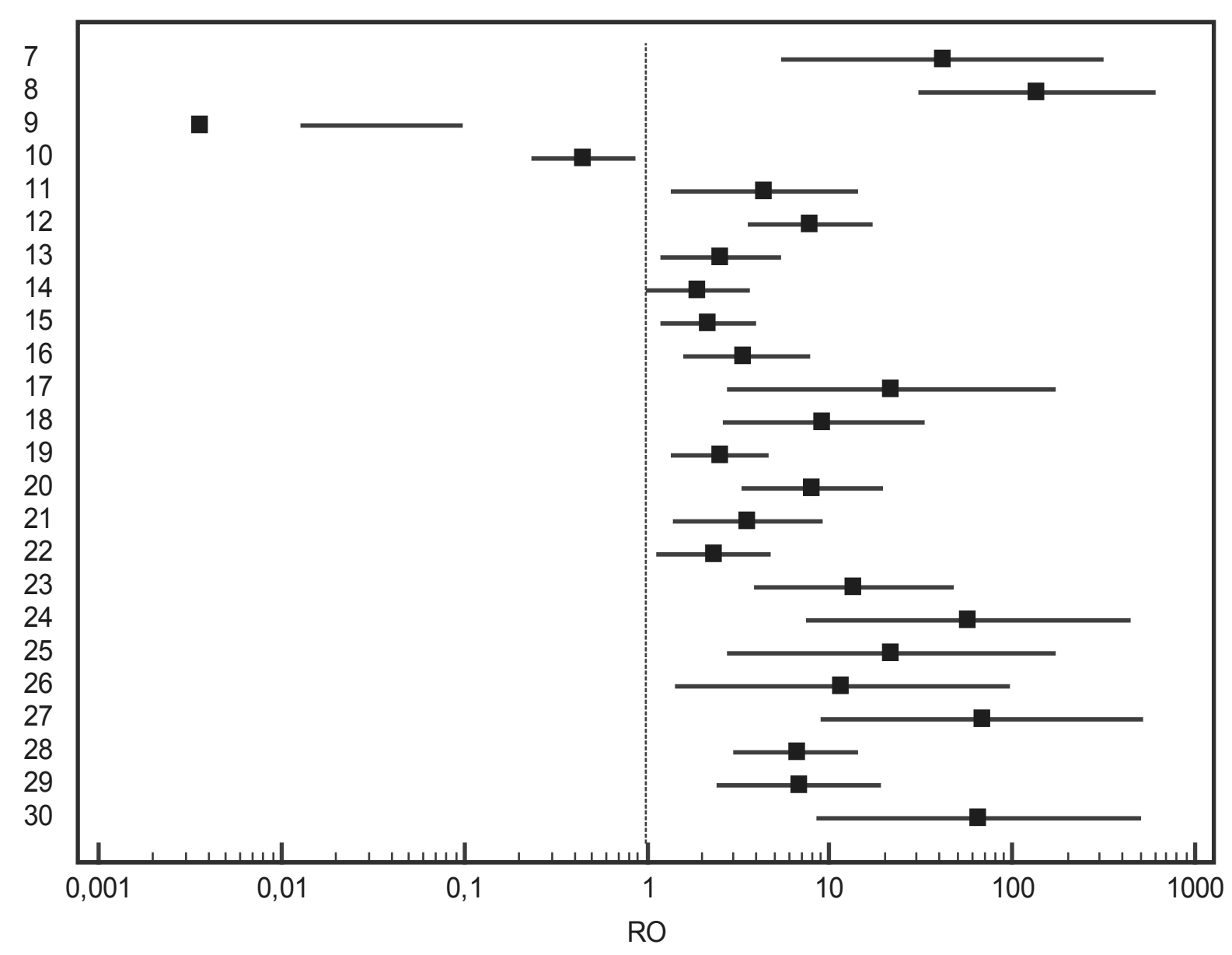

Диаграмма 2. Отношение шансов возникновения тяжелой асфиксии 
В зависимости от метода родоразрешения пациенток основной группы были проанализированы гистологические заключения последов. В результате были получены следующие данные: при обоих методах родоразрешения ведущее место имели инволюционно-дистрофические процессы в плаценте, на втором месте воспалительные изменения последа.

\section{Обсужление}

Определив факторы риска в группах сравнения, достоверно отличающихся друг от друга и коррелирующие с «тяжелой асфиксией» мы определили отношения шансов (RO) возникновения тяжелой асфиксии при воздействии различных факторов, представленные на форест-диаграмме.

Если RO>1- больше шансов обнаружить фактор в группе с неблагоприятным исходом (тяжелая асфиксия новорожденного).

Если $\mathrm{RO}<1$ - больше шансов обнаружить фактор в группе сравнения с благоприятным перинатальным исходом, т.е. состояние новорождненного по шкале Апгар 8-9 баллов.

95\% доверенный интервалом (ДИ) не равный единице указывает на то, что исследуемый признак имеет значимую статистическую связь.

7-наличие патологии околоплодных вод; 8-если поступает с «незрелой» шейкой матки; 9-если поступает с открытием маточного зева; 10-если поступает со «зрелой» шейкой матки; 11-если на скрининговом УзИ № 2 выявлена патология; 12- если на скрининговом УЗИ № 3 выявлена патология; 13 -роды в сроке более 40 недель; 14 -имеют средне-специальное образование; 15не имеют высшего образования; 16 -не имеют абортов в анамнезе; 17-имеют более одного аборта в анамнезе; 18-постановка на диспансерный учет по беременности после 12 недель беременности; 19 -имеют отягощенный акушерско-гинекологический анамнез; 20-наличие сердечно-сосудистой патологии; 21-наличие нарушений жирового обмена; 22-наличие инфекций мочевыводящих путей; 23- если не делали скрининговое УЗИ № 1; 24если использовали катетер Фоллея; 25- если использовали мифепристон; 26- если использовали гель; 27- если делали амниотомию; 28- если использовали окситоцин; 29- если использовали вакуумэкстрактор; 30-оперативное родоразрешение;

Анализ, проведенный с помощью вычисления отношения шансов показал, что шансы рождения плода в состоянии тяжелой асфиксии значительно повышаются если, в анамнезе у беременной было более одного абор- та (в 21,7), если на втором или третьем скрининговых ультразвуковых исследованиях была выявлена патология околоплодных вод (в 41,4) такая как маловодие, многоводие, взвесь. Если сравнить между собой срок родоразрешения, то роды с 34 по 37 неделю повышают шанс рождения пода в состоянии тяжелой асфиксии в 15,7 раз, а в сроке после 40 недель только в 2,5 раза. Шансы значительно повышаются если беременная поступает в акушерский стационар с «незрелыми» родовыми путями (в 137,9). Что касается продолжительности родов и безводного промежутка, то они достоверно отличались в группах сравнения, с прямой корреляционной зависимостью от исхода - чем дольше, тем исход хуже. В своей статье Баев О.Р., Рубцова С.В. и др. отмечают, что «в современном акушерстве определение границ естественной продолжительности родов затруднено в связи с широким распространением инструментальных и медикаментозных воздействий, одни из которых ускоряют, а другие замедляют их течение». Ухудшаются исходы, если в качестве метода подготовки шейки матки использовали катетер Фоллея (в 57,6), мифепристон (в 21,7), а в качестве метода родовозбуждения - амниотомию (в 68,6). Меньший риск был выявлен при использовании дипростон-геля (в 11,7) и окситоцина (в 6,7) в качестве методов индукции родов. Этот факт находит подтверждение в статье Баева О.Р., Бабича Д.А., которые в своем исследовании показали, что индукция родов при беременности «Full term» (284-285 дней) оказалась более эффективной, чем в группе «Late term» (287 дней и болеe). Следует отметить, что лучший исход наблюдается при самопроизвольном пусть и преждевременном разрыве плодного пузыря, чем при амниотомии.

\section{Зак^ючение}

Таким образом, в результате проведенного исследования были выявлены значимые факторы, приводящие к неблагоприятным перинатальным исходам. Факторы условно можно разделить на неуправляемые - на которые мы повлиять не можем и управляемые - зависящие от выбранной нами тактики ведения. К 30 годам беременные уже имеют отягощенный соматический анамнез по сердечно-сосудистой патологии и нарушению жирового обмена. Салов И.А. и др. в своем исследовании установили, что «наиболее вероятной причиной высокой частоты и тяжести асфиксии новорожденных является высокий уровень внутрибрюшного давления у рожениц с ожирением», что нашло отражение и в нашем исследовании. В условиях женской консультации это прежде всего ранняя явка и максимально быстрое обследование, включая ультразвуковой и биохимический скрининг до 12 недель беременности, чтобы решить вопрос о целесообразности пролонгирования беременности. Своевременное направление на второе и третье скрининговые УЗИ, на которых можно выявить такие факто- 
ры риска как многоводие, маловодие, внутриутробную задержку роста плода, нарушение маточно-плацентарного или фето-плацентарного кровотока. А вот следующий этап самый ответственный - при каких условиях поступать в акушерский стационар? Исходя из полученных нами данных идеальный вариант это - при доношенной беременности с открытием маточного зева или в отделение патологии беременных со «зрелой» шейкой матки. Но, учитывая тот факт, что в стационар 3 уровня поступают женщины «высокого» риска, то достаточно часто используются методы подготовки шейки матки, методы родовозбуждения и родостимуляции. «Влияние медицинских вмешательств на процесс родов часто ведет к их необоснованному применению, гипердиагностике аномалий родовой деятельности, результатом чего является возрастание частоты оперативного родоразрешения». (Баев О.Р. и др.) Необходим индивидуальный отбор беременных и подбор метода для программированных родов, ориентируясь не только на срок беременности, а в большей степени на готовность родовых путей.

\section{ЛИТЕРАТУРА}

1. Баев О.Р., Бабич Д.А. Сравнение эффективности индукции родов при беременности «Full term» и «Late term». Акушерство и гинекология. $2020 ; 2: 97-103$.

2. Баев 0.Р., Рубцова С.В., Васильченко 0.Н. и др. Продолжительность «нормальных» родов в современных условиях. Акушерство и гинекология. 2012; (1) 49-55.

3. Барановская Е.И., Будюхина 0.А., Баранчук С.А. Патоморфологическая характеристика хронической плацентарной недостаточности\ Журнал Здравооохранение, клиническая медицина № 8, 2011 год, стр. 4-9.

4. Будюхина О.А., Барановская Е.И., Даниленко Н.Г. и др. Перинатальные исходы плацентарной недостаточности в зависимости от генотипов глутатион-ऽ-трансфераз. Репродуктивное здоровье в Белоруссии 2010; (2): 59-68.

5. Низяева Н.В., Приходько А.М., Евграфова А.В. и др. Клинико-морфологические особенности плаценты при острой внутриутробной гипоксии в родах. Акушерство и гинекология 2019; (12) 96-104.

6. Палютина Е.Ю., Козловская И.А. Медико-социальные факторы риска тяжелой асфиксии новорожденных // Современная наука: актуальные проблемы теории и практики. Серия «Естественные и технические науки» 2020; № 5; 97-104;

7. Салов И.А., Маршалов Д.В., Петренко А.П. зависимость гипоксии плода от уровня внутрибрюшного давления в родах у пациенток с ожирением. Акушерство и гинекология. 2018; (2) 50-54.

8. Струков А.И., В.В. Серов В.В. Патогенез плацентарной недостаточности зависит от нарушений процессов имплантации и плацентации - аномалий прикрепления и строения плаценты, васкуляризации, дифференциации ворсин хориона. Патологическая анатомия: учебник / — 5-еизд., стер. 一 М.: Литтерра, 2010.- 880 с.: ил.

( П) Палютина Елена Юрьевна ( peyu260562@mail.ru), 